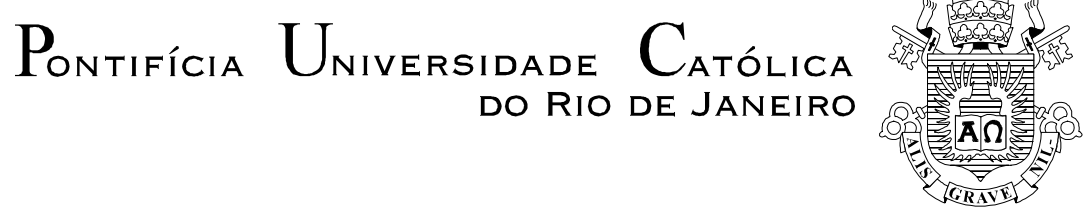

Danielle Zuma Capellani

\title{
A RETÓRICA DA NEUTRALIDADE EM REPORTAGENS DO JORNALISMO DE NEGÓCIOS
}

\section{Tese de Doutorado}

Tese apresentada ao Programa de PósGraduação em Letras da PUC-Rio como requisito parcial para obtenção do título de Doutor em Letras.

Orientadora: Profa. Maria do Carmo Leite de Oliveira Co-orientadora: Profa. Sonia Bittencourt Silveira

Rio de Janeiro março de 2010 


$$
\text { Pontifícia Universidade } \text { Católica }_{\text {Do Rio de Janeiro }}
$$

Danielle Zuma Capellani

\title{
A RETÓRICA DA NEUTRALIDADE EM REPORTAGENS DO JORNALISMO DE NEGÓCIOS
}

\begin{abstract}
Tese apresentada como requisito parcial para obtenção do grau de Doutor pelo Programa de Pós-Graduação em Letras do Departamento de Letras do Centro de Teologia e Ciências Humanas da PUC-Rio. Aprovada pela Comissão Examinadora abaixo assinada.
\end{abstract}

Profa. Maria do Carmo Leite de Oliveira

Orientadora

Departamento de Letras - PUC-Rio

Profa. Sonia Bittencourt Silveira

Co-Orientadora UFJF

Profa. Maria das Graças Dias Pereira

Departamento de Letras - PUC-Rio

Profa. Jackeline Lima Farbiarz PUC-Rio

Prof. Paulo Cortes Gago

UFJF

Profa. Amitza Torres Vieira

Faculdade de FCL Santa Marcelina

Prof. Paulo Fernando Carneiro de Andrade

Coordenador Setorial do Centro de Teologia

e Ciências Humanas - PUC-Rio

Rio de Janeiro, 05 de março de 2010. 
Todos os direitos reservados. É proibida a reprodução total ou parcial do trabalho sem autorização da autora, da orientadora e da universidade.

\section{Danielle Zuma Capellani}

Graduou-se em Comunicação Social - habilitação Jornalismo - na Universidade Federal de Juiz de Fora, em 1999, onde especializou-se em Processos Estratégicos, Comunicação e Novas Tecnologias, em 2002. Obteve o título de Mestre em Letras, pela UFMG- Universidade Federal de Juiz de Fora, em 2004. Tem experiência na área de Comunicação, com ênfase em Assessoria de Comunicação Empresarial. Leciona no Ensino Superior disciplinas relacionadas às Teorias da Comunicação, à Semiótica e à Interface entre Mídia e outros Contextos Profissionais.

Ficha Catalográfica

Capellani, Danielle Zuma

A retórica da neutralidade em reportagens do jornalismo de negócios / Danielle Zuma Capellani ; orientadora: Maria do Carmo Leite de Oliveira ; co-orientadora: Sonia Bittencourt Silveira. -2010.

216 f. : il. (color.) ; $30 \mathrm{~cm}$

Tese (Doutorado)-Pontifícia Universidade Católica do Rio de Janeiro, Departamento de Letras, 2010.

Inclui bibliografia

1. Letras - Teses. 2. Neutralidade jornalística. 3. Revista de negócios. 4. Estratégias argumentativas. 5. Posicionamento. I. Oliveira, Maria do Carmo Leite de. II. Silveira, Sonia Bittencourt. III. Pontifícia Universidade Católica do Rio de Janeiro. Departamento de Letras. IV. Título. 
Ao meu querido filho Olavo, companheiro de aventuras na vida.

À minha mãe, exemplo de mulher surpreendente. 


\section{Agradecimentos}

À CAPES, pelo apoio através da bolsa de fomento à pesquisa, que me auxiliou na realização deste estudo.

À Profa. Maria do Carmo Leite de Oliveira, orientadora atenta, incentivadora de todos os projetos apresentados ao longo desta jornada. Seu apoio na trajetória da pesquisa foi fundamental para que houvesse autonomia nas minhas escolhas. Lingüista com olhar treinado para as manifestações da linguagem e para as interações humanas, suas orientações me ajudaram nas lições da língua e da vida. Professora admirável, que acreditou no trabalho mesmo em momentos de maior dificuldade. Muito obrigada.

À Profa. Sonia Bittencourt Silveira, co-orientadora que abraçou o trabalho nos momentos finais e, de fato, me acompanhou na trajetória para que os dados fossem vistos com a "lente" adequada da teoria. A solidariedade e disponibilidade de sempre me encantaram como orientanda e, certamente, me guiarão como profissional. Muito obrigada.

A todos os colegas de Doutorado em Estudos da Linguagem da PUC-Rio, pelas trocas ricas em sala de aula e pelo auxílio em fazer o Rio se aproximar de Juiz de Fora. Agradecimento especial à Raquel Brigatte, amiga de viagens e de planos.

Aos amigos, que nem sempre compreenderam as ausências, mas torceram muito pelo sucesso do trabalho.

À toda a minha família, que se organizou para que fosse possível a conclusão deste trabalho e a realização de todos os meus sonhos.

Ao meu avô Sílvio (in memorian), que sempre me ensinou a ter fé e acreditar que as pessoas merecem ser felizes. Sinto muitas saudades. 
Ao meu pai (in memorian), cujo exemplo de leitor e de pesquisador interessado em usar os conhecimentos a serviço das pessoas gostaria muito de ter herdado.

À minha mãe, grande mulher, incentivadora e patrocinadora dos meus sonhos, desde sempre dando suporte para que eu possa caminhar com menos dificuldade na vida. Minha admiração e meu agradecimento são eternos.

Ao meu filho Olavo, quem mais conviveu com este trabalho e muitas vezes se valeu dele para justificar suas faltas. Sua compreensão e paciência me deixam muito orgulhosa.

A todos aqueles que, de uma maneira ou de outra, me ajudaram a realizar este trabalho. 


\section{Resumo}

Capellani, Danielle Zuma. Oliveira, Maria do Carmo Leite de. A Retórica da Neutralidade em Reportagens do Jornalismo de Negócios . Rio de Janeiro, 2010. 216p. Tese de Doutorado - Departamento de Letras, Pontifícia Universidade Católica do Rio de Janeiro.

A presente tese propõe uma discussão sobre a postura neutralística (Heritage; Greatbatch, 1991) adotada nas reportagens de capa da Revista Exame, da editora Abril, publicadas no ano de 2005. As reportagens são analisadas a partir das estratégias argumentativas (Vieira, 2003; Schiffrin, 1987; Gryner, 2000) de expressão de pontos de vista e de sustentação, por meio das quais a revista se posiciona e posiciona as organizações e os empresários (Harré; Langenhove, 1991; 1999) no mundo dos negócios. A partir da análise destas estratégias, foram verificadas as principais storylines de sucesso defendidas pela publicação, como princípios para as empresas crescerem com lucro. Os resultados apontam para o uso de estratégias de sustentação de argumentos com base em fatos; exemplos de outras empresas; dados estatísticos obtidos através de pesquisas e de discurso reportado (Tannen, 1989) de estórias de vida de empresários e especialistas, o que confere ao discurso jornalístico aparência de representar objetivamente a realidade (Shi-Xu, 2000). No entanto, estas estratégias lingüístico-discursivas expressam pontos de vista e aproximam o gênero reportagem do press release, isto é, de um texto que informa e promove as organizações, seus gestores e servem como cartilhas que orientam o comportamento profissional no mundo capitalista (Gee et. al., 1996).

\section{Palavras-chave}

Neutralidade jornalística; revista de negócios; estratégias argumentativas; posicionamento. 


\section{Abstract}

Capellani, Danielle Zuma. Oliveira, Maria do Carmo Leite de. The Rethoric of Neutrality in News Reports in Business Journalism. Rio de Janeiro, 2010. 216p. PhD Dissertation - Departamento de Letras, Pontifícia Universidade Católica do Rio de Janeiro.

This study proposes a discussion about the neutralistic posture (Heritage; Greatbatch, 1991) assumed on cover reports of Revista Exame published in 2005, Abril Publisher. The reports are analyzed based on the argumentative strategies (Vieira, 2003; Schiffrin, 1987; Gryner, 2000) of marks of points of view and sustaining, through which the magazine assumes a position while positions organizations and entrepreneurs (Harré; Langenhove, 1991, 1999) in the business world. The analysis of these strategies unveiled the main storylines of success spread by the magazine as principles for companies to grow profitably. The results show the use of strategies to sustain arguments based on facts; examples of other companies; statistical data from surveys and reported speech (Tannen, 1989) of life stories told by entrepreneurs and experts, making believe that journalistic discourse represents objectively the reality (Shi-Xu, 2000). However, these linguistic and discursive strategies express points of view and provide approximation between reports and press release, that is, a text that informs and promotes organizations and their managers and can be used as manuals to guide professional behavior in the capitalist world (Gee et. al., 1996).

\section{Keywords}

Journalistic neutrality; business magazine; argumentative strategies; positioning. 


\section{Sumário}

1. INTRODUÇÃO 18

1.1.Definição do problema 19

$\begin{array}{ll}1.2 \text { Perguntas de pesquisa } & 21\end{array}$

1.3. Objetivos gerais $\quad 22$

1.4. Objetivos intermediários 22

1.5. Justificativa 23

2. REFERENCIAL TEÓRICO 25

2.1. Mídia como construção social 26

2.1.1. Jornalismo de revista 29

2.1.2. Gênero textual jornalístico: a reportagem 31

2.1.3. Questões acerca da postura neutralística 34

2.2. Argumentação no jornalismo de negócios 38

2.2.1. Ponto de vista da publicação 40

2.2.2. Disputa 41

2.2.3. Estratégias de sustentação 42

2.2.4. Conclusão como ratificação do ponto de vista 43

2.3. Posicionamento como representação de atributos identitários 44

2.3.1. Macro storyline: a nova ordem do trabalho 49

2.3.2. Ações 51

2.3.3. Posições: projeção de atributos identitários 52

3. METODOLOGIA 53

3.1. Tipo de pesquisa 53

3.2. Geração de dados 54

3.3. Características do corpus 57

3.4. Categorias de análise 58

4. A CARTILHA DO SUCESSO 60

4.1. Cinco storylines do sucesso 61

4.1.1. Meritocracia 65

4.1.1.1. Meritocracia em empresas familiares 87

4.1.2. Inovação 120

4.1.3. Senso de oportunidade 139 
4.1.4. Moderação 142

4.1.5. Conhecimento dos clientes 145

4.2. Discussão dos resultados 150

5. CONCLUSÃO 159

6. REFERÊNCIAS BIBLIOGRÁFICAS 162

7. ANEXOS 170

7.1.Anexo 1 - Data de publicação, título e subtítulo da reportagem de capa e reprodução da imagem da capa das edições da revista 170 Exame publicadas no ano de 2005

7.2. Anexo 2 - Reportagem de capa da edição no 850

7.3. Anexo 3 - Reportagem de capa da edição no 851

7.4. Anexo 4 - Reportagem de capa da edição no 838

7.5. Anexo 5 - Reportagem de capa da edição no 856 


\section{Lista de Esquemas e llustrações}

Esquema 1 - Adaptação do modelo argumentativo

(Vieira, 2003, p. 54-55)

Esquema 2 - Síntese dos resultados encontrados

Ilustração 1 - Capa da edição 851

Ilustração 2 - Box com dados da Promon 72

Ilustração 3 - Box com lista do que as melhores empresas

valorizam e do que detestam nos funcionários

Ilustração 4 - Foto e texto legenda da funcionária da

Credicard Amélia Soares

Ilustração 5 - Texto legenda da funcionária da

Credicard Amélia Soares

Ilustração 6- Box com características das empresas inovadoras 


\section{Lista de Quadros}

Quadro 1 - Crescer é um imperativo para as empresas

$62-63$

Quadro 2 - Box identificando os cinco princípios ou as cinco torylines de crescimento

Quadro 3: Exemplo de prática meritocrática - funcionário da ALL

Quadro 4: Redução do custo fixo da empresa ALL ao aplicar a meritocracia

Quadro 5: Inspirador da meritocracia na ALL - Wal-Mart

Quadro 6: Promon - empresa no primeiro lugar do ranking Melhores Empresas para Você Trabalhar

Quadro 7: Em empresas que adotam práticas meritocráticas, os profissionais vêem como justa sua participação nos resultados

Quadro 8: Base da meritocracia - Ford

Quadro 9: Instaurar a meritocracia é difícil para as empresas Brasileiras

Quadro 10: Jack Welch confirma a importância da meritocracia

Quadro 11: Como a meritocracia é aplicada na Promon

Quadro12: Transparência aliada à meritocracia

Quadro 13: Para as empresas adotar a meritocracia é garantia de ter os profissionais mais preparados

Quadro 14: A meritocracia é incipiente no Brasil

Quadro 15: Exemplo da empresa norte-americana Southwest e da Home Depot

Quadro 16: Exemplo de empresa brasileira - Magazine Luiza

Quadro 17: Como se dá o processo meritocrático no Magazine Luiza

Quadro 18: A antropóloga Lívia Barbosa explica a vergonha dos brasileiros em serem os melhores 
Quadro 19: Recompensa com dinheiro e com elogios

Quadro 20: Dinheiro e elogios funcionam como recompensa mais satisfatória para os melhores funcionários

Quadro 21: Psicologia prevalece sobre Administração em empresas familiares

Quadro 22: Ponto de vista: discussões familiares repercutem na empresa

Quadro 23: Vantagens de discutir sobre as empresas familiares

Quadro 24: Ponto de vista: a empresa familiar é a mais antiga instituição existente

Quadro 25: Ponto de vista: a importância das empresas familiares

Quadro 26: Definição do que é uma empresa familiar

Quadro 27: Contraponto entre empresas familiares e não familiares

Quadro 28: Os problemas das empresas familiares podem piorar no momento da sucessão

Quadro 29: Exemplos de sucessão mal desenvolvidos:

Cofap e Lacta

Quadro 30: Tema - a escolha de herdeiro x escolha de executivo - o que diferencia essas duas escolhas? Sucessão na família ou fora dela $100-101$

Quadro 31: Pais que permitem a sucessão da empresa aos filhos 102

Quadro 32: Requisitos para uma sucessão bem desenvolvida:

o papel da meritocracia

Quadro 33: : Transferência de gestão entre parentes (amadorismo) x transferência de gestão para outros empresários (profissionalismo)

Quadro 34: Vantagens e desvantagens de trabalhar em empresa familiar

Quadro 35: Posições conflitantes de fundadores x herdeiros e ambivalência pai-patrão

Quadro 36: Metáfora do sistema solar - apenas uma estrela posicionada como centro e como tendo luz própria, as demais posições são para estrelas com menos brilho 
Quadro 37: Filhos de profissionais liberais: o problema da identificação e da diferenciação

Quadro 38: A relação do fundador com a empresa e com o filho 110 - 111

Quadro 39: A receita do sucesso dos herdeiros nas empresas Familiares

Quadro 40: Clã Klein

Quadro 41: Clã Jatene

Quadro 42: Clã Alencar

Quadro 43: Clã Aguiar

Quadro 44: Clã Musa

Quadro 45: Clã Veirano

Quadro 46: Inovar é essencial ao crescimento, com a ressalva de que nem sempre isso faz parte da realidade da empresa e as grandes inovações raramente se repetem ao longo do tempo

Quadro 47: As inovações mais comuns são as mais simples

Quadro 48: Cenário nacional da inovação: exemplo da

Perdigão - cautela e inovação

Quadro 49: Ponto de vista: há determinados atributos próprios do inovador - quais são eles e como devem ser aplicados na empresa para gerar lucro

Quadro 50: Características dos inovadores devem ser partilhadas pelo grupo

Quadro 51: Inovar é essencial para as empresas, caso contrário elas morrem

Quadro 52: Para inovar não é preciso aplicar muito dinheiro

Quadro 53: A inovação está centrada nos consumidores

Quadro 54: Foco na criação é fundamental

Quadro 55: PV: Apple - investimento maior em cérebro 
Quadro 57: Natura como exemplo da estratégia de inovação em mercados emergentes

Quadro 58: Chega de pesquisa

Quadro 59: Procter \& Gamble: inovação a partir da valorização do Design

Quadro 60: Procter \& Gamble: observação dos consumidores

Quadro 61: O produto que salvou uma empresa

Quadro 62: Nutrimental - ensinamentos aprendidos com a crise

Quadro 63: Características de empresas inovadoras em geral mobilização das equipes e quebra da inércia

Quadro 64: O princípio do senso de oportunidade ocorre no início da estória dos empreendedores, mas é difícil de ser adotado depois de consolidada a empresa

Quadro 65: Exemplo da Nortox como empresa que teve senso de oportunidade

Quadro 66: Ter senso de oportunidade pode significar ser seguidor de um novo mercado

Quadro 67: Paradoxo aparente entre crescimento e princípio da moderação

Quadro 68: Exemplo de moderação no Brasil - Dpaschoal

Quadro 69: Como se deu o crescimento da DPachoal de forma moderada

Quadro 70: Exemplos da ALL e da Visanet de como conhecer os clientes promove crescimento com lucro

Quadro 71: Exemplo da Visanet - união dos princípios de conhecimento dos clientes e inovação

Quadro 72: Visanet - exemplo de um dos escritórios da empresa

Quadro 73: Retomada geral de todos os princípios e dos exemplos 


\section{Lista de Tabelas}

Tabela 1- llustração e características do corpus principal 54 - 55

Tabela 2- Princípio da Meritocracia 152

Tabela 3- Princípio da Meritocracia 153

Tabela 4- Princípio da Meritocracia nas empresas 154

$\begin{array}{ll}\text { Tabela 5- Meritocracia } & 154\end{array}$

Tabela 6- Princípio da inovação 155

$\begin{array}{ll}\text { Tabela 7- Posicionamentos } & 155-156\end{array}$

Tabela 8- Princípio de senso de oportunidade 156

Tabela 9- Princípio de senso de oportunidade 156

$\begin{array}{ll}\text { Tabela 10- Princípio da moderação } & 157\end{array}$

Tabela 11- Princípio da moderação 157

Tabela 12- Princípio do conhecimento do cliente 157

Tabela 13- Princípio do conhecimento do cliente 158 
"O que não o mata o fortalece."

Friedrich Nietzsche (Ecche Homo, p. 25) 